\title{
Patterns audiovisualísticos - o fenômeno audiovisual da animação sob o ponto de vista do design
}

\section{Audiovisualistics Patterns - the audiovisual phenomenon of animation by the viewpoint of design}

Tiago Ribeiro ${ }^{1}$

Marcelo Silva ${ }^{2}$

Berenice Gonçalves ${ }^{3}$

Milton Vieira ${ }^{4}$

Gilson Braviano ${ }^{5}$ 


\section{Resumo}

Em tempos onde a produção de animações brasileiras ganha cada vez mais espaço na televisão nacional, tornase necessário identificar os processos de construção desse tipo de produto, visando o aperfeiçoamento dos procedimentos e profissionais de animação do país. Assim, busca-se com este artigo abordar e discutir a relação entre o design e as interfaces audiovisuais. Tendo em vista a interpretação do design como disciplina facilitadora do acesso à informação em produções audiovisuais que se utilizando dos preceitos da linguagem visual, este trabalho aborda as interfaces audiovisuais e suas relações com o design e a animação, sob o ponto de vista do tempo, ritmo, velocidade, sequência e linguagem visual. Para tanto é feita, a partir de uma aproximação exploratória e descritiva, a exposição do trecho de uma animação utilizando os conceitos propostos na retórica audiovisualística de Gui Bonsiepe (2011), que entende o todo audiovisual como uma interface, no intuito de buscar uma forma de ver e descrever a mídia audiovisual pelo ponto de vista do design. $O$ trecho escolhido para exposição faz parte da série brasileira Irmão do Jorel, selecionada para este trabalho

\section{Abstract}

In times where Brazilian production of animation is gaining more ground in national television, it becomes necessary to identify the construction processes used in these kind of products, aiming the improvement of both these procedures and Brazilian professionals of this area. Thus, this article intends to approach and discuss the intersection between design and audiovisual interfaces. Seeing the design as a facilitating discipline to access to information on audiovisual productions using the precepts of visual language, this paper deals with the meeting of these two disciplines under the point of view of time, rhythm, speed, sequence and visual language. For this purpose, from an exploratory and descriptive approach, it is exposed an excerpt of an animation using the concepts proposed on "audiovisualistic rhetoric" of Gui Bonsiepe, who understands all the audiovisual as an interface in order to look for audiovisual media at the design point of view.

Keywords: animation, brazilian animation, audiovisual rhetoric, audiovisual interfaces. 
por se tratar da primeira série de animação inteiramente produzida na América Latina, veiculada pelo canal de televisão (TV) Cartoon Network; e que faz parte de uma recente remessa de animações brasileiras que passou a integrar a grade dos canais de TV por assinatura.

Palavras-Chave: animação, animação brasileira, retórica audiovisual, interfaces audiovisuais.

ISSN: $1808-3129$

1 tiago.oriebir@gmail.com

2 marcelo@rizoma.com.br

3 berenice@cce.ufsc.br

4 milton@cce.ufsc.br

5 gilson@cce.ufsc.br 


\section{Introdução}

De acordo com CHONG (2011), a animação pode ser definida como uma técnica em que se cria a ilusão de movimento para um público por meio da apresentação de uma sequência de imagens em rápida sucessão. A palavra animação vem do verbo animar e, conforme o dicionário Houaiss, significa dar alma, dar vida a alguma coisa, imprimir ação, movimento ou aceleração; dar a aparência de vida. A palavra tem origem do verbo latino animare (dar vida a) e só passou a ser utilizada para descrever imagens em movimento a partir do século XX (BARBOSA JÚNIOR, 2005).

Atualmente existem muitas maneiras de se produzir animações, que variam desde técnicas tradicionais de desenho até a programação de personagens em softwares 3D, passando pela utilização da captura fotográfica de modelos reais, técnica conhecida como stop-motion e pela criação de imagens 2D em desenhos digitais, entre outras - estas técnicas inclusive podem ser mescladas entre si, gerando estilos de animação completamente originais. Independente do estilo e da sofisticação tecnológica, existem elementos fundamentais que permanecem imutáveis da qual a animação dispõe, como a sequência de imagens que promove a criação da ilusão de ótica em si e a não-perfeição na simulação das formas resultantes e da limitação das formas (CHONG, 2011).

As raízes da animação estão intrinsecamente ligadas aos trabalhos experimentais dos pioneiros do cinema; e muito do que foi desenvolvido na área desde sua origem até a contemporaneidade permanece com esta ligação. O mesmo pode-se dizer sobre os trabalhos de análise da área. Por mais que existam várias abordagens metodológicas diferentes no campo da análise fílmica, sua raiz é sempre, ligada ao cinema ou sua narrativa, em última instância. Este trabalho busca esquivar-se da abordagem cinematográfica, no intuito de apresentar um produto de animação sob o ponto de vista do design, entendendo que ambas as áreas compartilham a característica de produzirem artefatos com enunciação visual e estratégias estéticas de discurso; e que esta exposição pode contribuir para ambos os campos, conforme será aprofundado adiante.

\section{Ambiente da produção brasileira de animação para televisão}

O contexto da produção de animação no Brasil vem passando por um processo de mudança e expansão nos últimos anos. A permissão de que as concessionárias de telefonia utilizassem suas redes para fornecer serviços de TV paga permitiu que mais brasileiros tivessem acesso aos serviços de televisão por assinatura em conjunto com outros produtos, tais como banda larga e telefonia, em um formato de pacote de serviços que permitiu o barateamento do preço pelo uso da TV por assinatura. A sanção da lei 12.485 , em julho de 2011, foi um fato importante nesse contexto, uma vez que estabeleceu para os canais de televisão (TV) por assinatura uma quantidade mínima de tempo de exibição dedicada somente a conteúdos brasileiros, sendo que ao menos metade deste conteúdo deveria ser produzido por produtoras brasileiras independentes (PRESIDÊNCIA DA REPÚBLICA, 2011). Esta legislação vem promoven- 
do um fortalecimento das produtoras de animação brasileiras, pois muitos dos canais de TV por assinatura dedicam-se parcial ou totalmente em apresentar séries e filmes de animação em sua programação.

Em um universo saturado de super-heróis, a riqueza da cultura brasileira tem feito a diferença na produção de animações. O Brasil, que até poucos anos, exportava apenas seus profissionais da área, agora está exportando também seus produtos para diferentes países do mundo (CULTURA E MERCADO, 2012). Aproveitando essa oportunidade, as animações brasileiras estão conquistando seu espaço na televisão e também na preferência do público. De acordo com o jornal O Globo (2012), bons exemplos desta realidade são as séries Historietas Assombradas, que em 2012, ano de seu lançamento, conquistou a maior audiência entre os canais pagos infantis, e Peixonauta (2009), que já é transmitida em 72 países.

De acordo com a Agência Nacional do Cinema (ANCINE, 2013), o mercado de obras de animação, devido suas caracteristicas, tem menos barreiras etárias, geográficas e de idioma. É um campo de inovação permanente na tecnologia e na criação artística. Nos últimos anos, algumas produtoras brasileiras tem conseguido posicionar suas obras no mercado internacional de TV. A ANCINE (2013) apresenta metas ambiciosas para a produção de animações no Brasil visando chegar ao número de 10 longas metragens em animação exibidos em salas de cinema até 2020 e a produção de cerca de 250 obras seriadas de animação até esse mesmo ano.

Ainda de acordo com o órgão, existem atualmente, mais de 200 festivais, mostras e eventos regulares de exibição audiovisual no Brasil, muitos deles exclusivos para animação - como é o caso do Animamundi, o segundo maior festival de animação do mundo - que auxiliam na difusão e comercialização das obras de animação produzidas no Brasil.

Todos estes fatos evidenciam a importância da área como campo de produção de pesquisa acadêmica, pois trata-se de um mercado com relevância social, tanto pelo ponto de vista da produção, gerando empregos e demanda de qualificação técnica, quanto pelo viés cultural, por promover ao público a possibilidade de consumir produtos desenvolvidos no país, podendo em decorrência disso fomentar o enriquecimento e fortalecimento da identidade cultural brasileira.

Isto posto, este artigo estabelece como objeto de estudo uma série de animação brasileira produzida recentemente, a partir da qual será feita a exposição de um trecho selecionado de um de seus episódios sob a ótica das seis dimensões de meios baseados em tempo proposta por Gui Bonsiepe e explicadas a fundo na terceira parte deste artigo, com a intenção de entender os objetivos e critérios adotados para a concepção adequada deste tipo específico de produto sob o viés do design.

Pretende-se, desta maneira, usar essas informações, para a construção de conteúdo que sirva como base decisória para a produção de animações voltadas ao público brasileiro.

\section{0 uso de patterns para a representação audiovisualística}

A representação de uma peça audiovisual sob a ótica do design é uma atividade incomum. Conforme Bonsiepe (2011), quase todas as pesquisas sobre retóri- 
cas na mídia audiovisual concentram-se no cinema, o que gera uma predominância de termos cinematográficos neste tipo de exposição. Bonsiepe expõe exemplos de análises audiovisuais que não se concentram em aspectos cinematográficos mas em "microestruturas audiovisualísticas não necessariamente ligadas a um filme" (BONSIEPE, 2011).

O que Bonsiepe propõe são indicações para a representação da mídia audiovisual pelo viés do design, partindo da verificação retórica do produto audiovisual - mas colocando em segundo plano a divisão clássica da retórica em figuras de palavras, de orações e semânticas e a tentativa de buscar alguma relação entre estas e possíveis equivalentes nas mídias audiovisuais - preferindo ir além da constatação dos elementos textuais, porque a mídia audiovisual "estabelece relações transversais entre as mídias, fazendo ligações entre elas e levando-as a um contexto ordenado" (BONSIEPE, 2011).

Bonsiepe deixa claro que a definição unidimensional entre texto e metatexto da retórica clássica não é suficiente para a representação da mídia audiovisual, de modo que expande este tipo de discurso em sete dimensões, por conta das variáveis que devem ser consideradas em sua exposição. Estas dimensões são A dimensão da Imagem, Som, Música, Texto visual, Texto Auditivo, Movimento e Interação; e estão esquematizadas de acordo com seus meios na Figura 01 a seguir.

\section{Retórlca audlovlsualístlca}

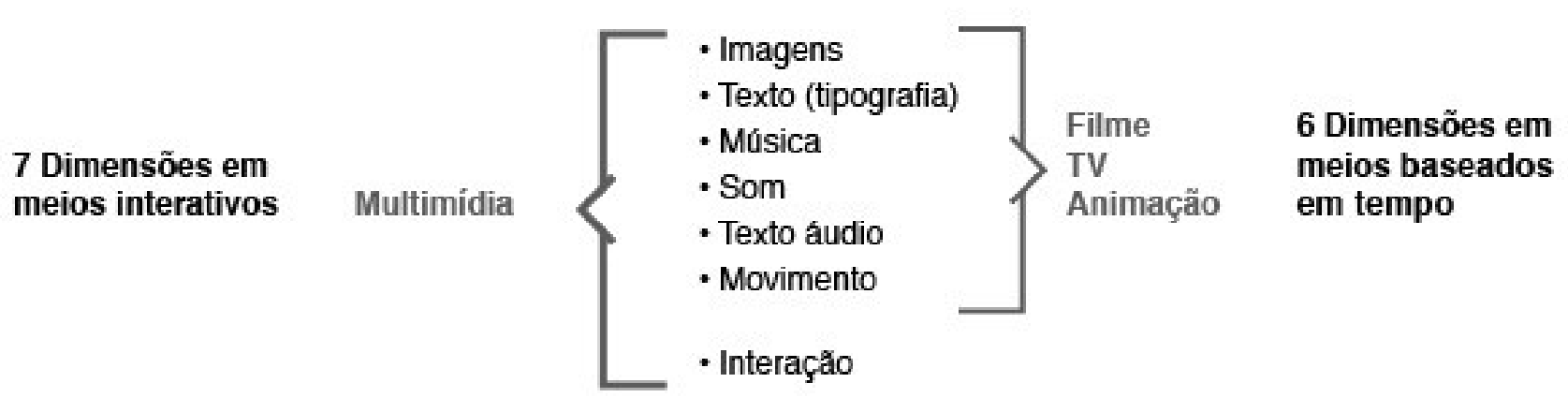

Figura 1 - As sete dimensões de retórica audiovisualística; divididas entre dimensões em meios baseados em tempo e dimensões em meios interativos. Fonte: os autores, adaptado de BONSIEPE, 2011, p.142.

A partir do exposto, este trabalho preocupa-se em aprofundar o conhecimento a respeito da produção de animações. Este tipo de produto pode estar presente em produções multimídia mas não é multimídia em si, o que a caracteriza como meio audiovisual baseado em tempo, de modo que na posterior exposição objeto deste trabalho foi desconsiderada a dimensão da Interatividade, particular de produtos multimídia.

Conforme traz Soares (1995), o discurso retórico tem não apenas a estratégia da persuasão, mas também a de sedução. Bonsiepe (2011) reflete sobre essa estratégia retórica geralmente não ser considerada séria no campo científico, mas afirmando que esta visão é limitada, definindo a estratégia de sedução como um elogio da su- 
perfície, das aparências. Ele apropria-se também da formulação de Jean Baudrillard, que denomina a retórica como uma área que trata de "estratégias de aparências", salientando que este é um dos principais aspectos do design.

Entretanto, Bonsiepe (2011) deixa claro que, apesar de sua ligação com as superfícies, o design não está limitado a isso, agindo como instância mediadora entre os artefatos e os usuários, com a dimensão estética participando do processo projetual de maneira constitutiva.

\footnotetext{
Enquanto a dimensão estética, do ponto de vista linguístico-analítico, pertence ao campo dos julgamentos (assessments) e não ao campo das afirmações (affirmations), é compreensível a postura reservada das ciências, pois elas visam a produção de afirmações verificáveis, baseada na evidência dos fatos, e não em julgamentos. Estes, em geral, baseiam-se em padrões não explícitos (subjetivos). (BONSIEPE, 2011. p. 145-146)
}

Esta ligação com a análise dos julgamentos (assessments), apesar das posíveis críticas observadas, é o que permite aos estudos em design fazerem análises semióticas sintáticas (da figura de um signo) e semânticas (do significado de um signo). Bonsiepe baseou-se na terminologia proposta pelo professor Christopher Alexander, que empregou o termo pattern pela primeira vez nesta área em seu livro A Pattern Language, de 1977, em que propõe uma catalogação dos tipos de problemas que podem surgir em um projeto, propondo uma solução a cada um deles. Para designar as estruturas repetitivas de signos presentes na retórica, chamando-as de patterns (padrões), que são o resultado da exposição das dimensões de retórica audiovisualística. Estas características, de apropriar-se das dimensões tempo e espaço do produto audiovisual, entendendo-o como elemento articulador de pesquisas teórico-críticas e a iniciativa em buscar a interdisciplinaridade e transversalidade (CAPES, 2013) entre o design e o cinema de animação, justifica o uso da representação audiovisualística baseada em patterns como adequado na atividade de design, por ser um elemento de ligação que faz a relação entre a área e a retórica da mídia audiovisual.

\section{Procedimentos metodológicos}

Segundo Bonsiepe (2011), os fenômenos audiovisuais só poderiam ser registrados e assimilados em um sistema de formas e apresentação visual que entrasse em diálogo com as formas de apresentação visual-auditivas, devendo ir além da retórica literária, de modo que o autor propõe a representação das patterns encontradas sob a forma de linha do tempo. Dessa maneira, o procedimento de representação audiovisual se deu a partir de quatro etapas, a saber:

Etapa 1 - Escolha do objeto de estudo (episódio de série de animação para TV) a ser analisado;

Etapa 2 - Seleção do trecho do episódio a ser analisado;

Etapa 3 - Identificação dos patterns audiovisualísticos encontrados no trecho analisado;

Etapa 4 - Desenvolvimento de diagrama audiovisualístico. 
Na primeira etapa, o objeto de pesquisa escolhido para a realização deste trabaIho foi a série Irmão do Jorel - criada e dirigida por Juliano Enrico e produzida pelo canal de TV Cartoon Network e Copa Studio. A primeira temporada é composta por 26 episódios, cada um com doze minutos de duração. A primeira exibição da série aconteceu em 22 de setembro de 2014. que teve sua estréia em setembro de 2014 no canal de TV por assinatura Cartoon Network. Além do fato de ser uma produção recente e veiculada em âmbito nacional, os outros critérios que influenciaram na definição deste objeto foram o fato de se tratar de uma obra completamente criada e desenvolvida no Brasil e de ser a primeira série original produzida pela Cartoon Network na América Latina. Além disto, esta foi a série de animação mais assistida na filial brasileira do canal no ano de 2014 (ABPITV, 2015); também tendo sido lançada para os demais países da América Latina em fevereiro de 2015 (LA NACIÓN, 2015).

A série aborda o cotidiano de uma excêntrica família. O personagem principal é o filho mais novo, um garoto cujo nome não é revelado, sendo conhecido apenas como "irmão do Jorel". Isso se dá porque ele vive ofuscado pela popularidade de seu irmão mais velho. Por conta disso, o garoto está sempre em busca de algo que o faça ser reconhecido. Nesse contexto, o garoto e seus parentes passam por diversas situações características de uma família brasileira típica no final da década de 1980.

Dos vinte e seis episódios da primeira temporada, o primeiro foi escolhido como objeto deste procedimento porque, de acordo com WHITE (2006), é esperado que no episódio de estréia ocorra uma apresentação dos personagens e circunstâncias da história. A não ser que o primeiro episódio tenha deliberadamente a intenção de chocar, enganar ou confundir o espectador, o público precisa ser introduzido ao mundo que será apresentado. Da mesma forma, FIELD (2001) também afirma que tudo em um roteiro está relacionado, de modo que é essencial introduzir os componentes da narrativa desde o início.

Cada episódio da série possui entre dez e onze minutos de duração, de modo que, dado o volume de informação que uma exposição audiovisualística pode gerar, foi necessária uma segunda etapa de refinamento para selecionar um trecho específico do espisódio, para que todo o procedimento pudesse ser contemplado em um artigo. Dessa forma, selecionou-se o primeiro minuto do episódio, desconsiderando a abertura, pois nesse intervalo de tempo acontece a apresentação do personagem principal e seu objetivo no episódio, bem como também são mostrados outros personagens e é possível ter um vislumbre da direção de arte da série.

\section{Resultados}

$\mathrm{Na}$ terceira etapa do processo foi realizada a identificação dos patterns. BONSIEPE (2011) não estabelece parâmetros teóricos claros a respeito da categorização de patterns dentro das seis dimensões audiovisualísticas, de modo que a representação audiovisual foi feita levando em conta as seis dimensões, ficando a tarefa de classificar categorias destas dimensões reservadas a um trabalho futuro, exclusivo a isto, dada a complexidade desta atividade. Todas as seis dimensões foram identificadas no trecho representado, sendo elas: (1) a dimensão de texto, relativa à inser- 
Ção de tipografia na animação; (2) a dimensão de música, relacionada à presença de música instrumental ou cantada compondo a mídia; (3) a dimensão de som, relativa aos efeitos especiais e elementos sonoros ambientais e contextuais encontrados; (4) a dimensão de texto áudio, que diz respeito à presença de falas dos personagens; (5) a dimensão de movimento, que dizem respeito à presença de imagens dispostas sequencialmente, bem como mudanças de planos; e (6) a dimensão de imagem que, além da óbvia presença, necessária para a existência da mídia animada, indicou também as mudanças de estilo na arte das imagens.

$\mathrm{Na}$ quarta etapa, identificadas a presença das dimensões no trecho audiovisual selecionado, foi desenvolvido o diagrama audiovisualístico, que possui o intuito de tabelar e apresentar visualmente as informações apontadas. Como BONSIEPE (2011) afirma, as interações entre imagens, texto, música e som são praticamente impossíveis de serem transmitidas textualmente. O autor então recomenda que sejam utilizadas como técnicas de representação, ferramentas afins às mídias baseadas em tempo. Assim, o diagrama audiovisualístico assume a configuração aproximada à linha de tempo de um software de edição de vídeos. Desta forma, chegou-se ao diagrama que representa o processo realizado, como pode ser aferido na Figura 2, a seguir.

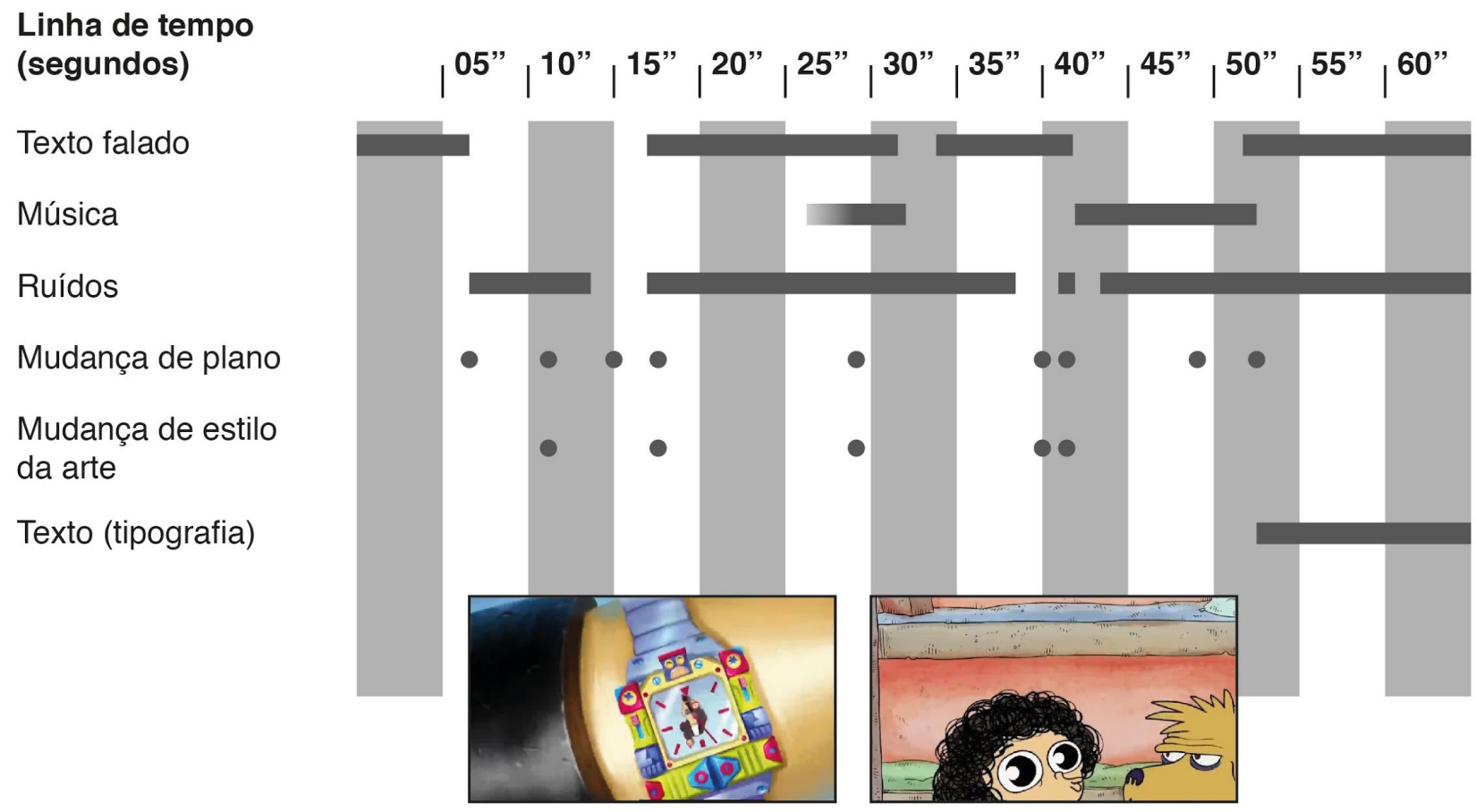

Figura 2 - Diagrama audiovisualístico resultante da exposição do trecho de animação selecionado. Fonte: os autores.

A descrição audiovisualística proposta por BONSIEPE (2011), tem potencial para se tornar uma notável ferramenta de pesquisa em design e animação, por unificar o ponto de vista da primeira disciplina em prol da segunda. O diagrama audiovisualístico é um recurso de data visualization que, segundo FRIENDLY (2009) trata-se da constatação e organização visual de dados de forma esquemática, incluindo características e variáveis das unidades de informação. O processo de retórica audiovisualística tem potencial por representar a inserção do ponto de vista do designer na 
representação de produtos audiovisuais. Entretanto, a forma como foi proposto não oferece um aprofundamento a respeito das categorizações das dimensões indicadas. Faz-se necessário um trabalho de categorização dessas dimensões, pois apenas desta maneira será possível tornar a caracterização de peças audiovisuais baseada na retórica audiovisualística mais objetiva e assertiva.

É compreensível que muitas interpretações possam ser feitas a partir das dimensões, podendo tornar o processo de categorização algo muito complexo, mas ao menos as categorias mais prementes devem ser definidas para atingir este objetivo. 0 próprio Bonsiepe oferece sugestões de categorização para as dimensões de música e som, tornando muito mais fácil acercar-se a respeito do alcance das mesmas. Todavia, a maneira como o autor apresenta sua proposta é desorganizada. Não há uma contextualização textual clara de vários elementos, ocorrendo sua apresentação somente por meio de exemplos de atividades de alunos seus, fazendo com que o leitor tenha que interpretar algumas informações baseado somente nestas imagens.

\section{Considerações finais}

Há de se compreender que os exemplos apresentados no artigo de Bonsiepe são de spots publicitários e peças isoladas de design, não existindo qualquer menção à animação em si - nem mesmo no esquema de definição das dimensões, adaptado neste trabalho na figura 1, onde os autores inseriram a animação junto da TV e do filme. Como foi mostrado neste artigo, a animação é uma mídia audiovisual como as demais e, portanto, passível de ser interpretada por esse viés. Isto posto, aponta-se a necessidade de ao menos dois novos trabalhos advindos deste, um buscando a categorização de todas as dimensões audiovisualísticas e outro fazendo a representação de um episódio, ou trecho, de animação brasileira levando em conta não somente as seis dimensões, mas também todas as suas categorias mais proeminentes. Uma vez atingido sucesso nestes dois trabalhos, os patterns audiovisualísticos poderão mostrar-se um código de representação de mídias audiovisuais poderoso por alicerçar a visão do designer sobre a produção audiovisual.

\section{Referências}

ALEXANDER, Christopher; ISHIKAWA, Sara; SILVERSTEIN, Murray. A Pattern Language: Towns, Buildings, Construction. New York: The Oxford University Press, 1977.

AGÊNCIA NACIONAL DO CINEMA (ANCINE). Plano de diretrizes e metas para o audiovisual. 2013. Disponível em: <http://www.ancine.gov.br/sites/default/files/folhetos/PDM\%202013.pdf>. Acesso em 5 de maio de 2015.

ASSOCIAÇÃO BRASILEIRA DE PRODUTORAS INDEPENDENTES DE TELEVISÃO (ABPITV). "Irmão do Jorel" é o desenho mais visto do Cartoon em 2014. Disponível em <http://abpitv.com.br/site/irmao-do-jorel-e-o-desenho-mais-visto-do-cartoon -em-2014/>. Acesso em 12 de maio de 2015. 
BARBOSA JÚNIOR, Alberto Lucena. Arte da Animação: técnicas e estética através da História. São Pauo: Editora Senac, 2002.

BONSIEPE, Gui. Design, cultura e sociedade. São Paulo: Blucher, 2011.

CHONG, Andrew. Animação Digital. Porto Alegre: Bookman, 2011. Disponível parcialmente em: <https://books.google.com.br/books?id=Blm2AwAAQBAJ\&printse-

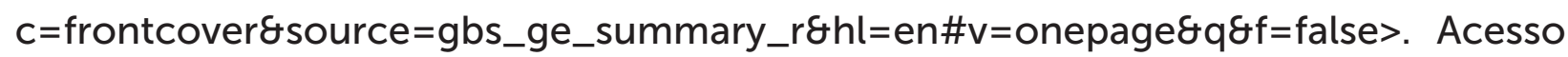
em 5 de maio de 2015.

COORDENAÇÃO DE APERFEIÇOAMENTO DE PESSOAL DE NÍVEL SUPERIOR (CAPES). Documento de Área de Arquitetura, Urbanismo e Design. Disponível em <https:// www.capes.gov.br/images/stories/download/avaliacaotrienal/Docs_de_area/Arquitetura_Urbanismo_e_Design_doc_area_e_comiss\%C3\%A3o_16out.pdf> Acesso em 6 de maio de 2015.

CULTURA E MERCADO. Mercado de animação no Brasil cresce em número e em importância. Disponível em: <http://www.culturaemercado.com.br/mercado/mercado-de-animacao-no-brasil

-cresce-em-numero-e-importancia/>. Acesso em 6 de maio de 2015.

FIELD, Syd. Manual do Roteiro. Rio de Janeiro: Objetiva, 2001.

FRIENDLY, Michael. Milestones in the history of thematic cartography, statistical graphics and data visualisation. Disponível em: <http://www.math.yorku.ca/SCS/Gallery/ milestone/milestone.pdf>. Acesso em: 13 de maio de 2015.

O GLOBO. Produção de seriados de animação brasileiros se firma com 30 novos projetos em curso. Disponível em: <http://oglobo.globo.com/cultura/producao-de-seriados-de-animacao-brasileiros

-se-firma-com-30-novos-projetos-em-curso-5502416>. Acesso em 3 de junho de 2015.

LA NACIÓN. Serie animada brasileña "El Hermano del Jorel" se ríe de los típicos hogares sudacas. Disponível em: <http://www.lanacion.cl/noticias/cultura-y-entretencion/tv/serie-animada-brasilena-hermano-de-jorel-se-rie-de-los-tipicos-hogaressudacas/2015-01-29/151845.html>. Acesso em 12 de maio de 2015.

PRESIDÊNCIA DA REPÚBLICA. Lei no 12.485, de 12 de setembro de 2011. Disponível em: <http://www.planalto.gov.br/ccivil_03/_Ato2011-2014/2011/Lei/L12485.htm>. Acesso em : 5 de maio de 2015.

SOARES, Murilo Cesar. Construindo o significado do voto: retórica da propaganda política pela televisão. Tese de doutorado. Departamento de Comunicação e Artes da Escola de Comunicações e Artes, Universidade Federal de São Paulo, 1995. 
Patterns audiovisualísticos - o fenômeno audiovisual da animação sob o ponto de vista do design

WHITE, Tony. Animation from Pencils to Pixels - Classical Techniques for Digital Animators. Oxford: Elsevier, 2006. 